\title{
Les limites de siècles. Lieux de ruptures novatrices depuis les Temps modernes
}

Annie Duprat

\section{(2) OpenEdition \\ 1 Journals}

Édition électronique

URL : https://journals.openedition.org/ahrf/1001

DOI : 10.4000/ahrf.1001

ISSN : 1952-403X

Éditeur :

Armand Colin, Société des études robespierristes

Édition imprimée

Date de publication : 1 décembre 2000

Pagination : 158-159

ISSN : 0003-4436

Référence électronique

Annie Duprat, "Les limites de siècles. Lieux de ruptures novatrices depuis les Temps modernes »,

Annales historiques de la Révolution française [En ligne], 322 I octobre-décembre 2000, mis en ligne le 26 avril 2006, consulté le 24 avril 2022. URL : http://journals.openedition.org/ahrf/1001 ; DOI : https:// doi.org/10.4000/ahrf.1001

Ce document a été généré automatiquement le 24 avril 2022.

Tous droits réservés 


\title{
Les limites de siècles. Lieux de ruptures novatrices depuis les Temps modernes
}

\author{
Annie Duprat
}

\section{RÉFÉRENCE}

Les limites de siècles. Lieux de ruptures novatrices depuis les Temps modernes. Actes du colloque international organisé par le laboratoire littérature et histoire des pays de langues européennes à Besançon, les 29-30-31 mai 1997, 779 pages en 3 vol., Presses universitaires Franc-Comtoises, collection Annales littéraires, 668.

1 Les Actes de ce colloque ambitieux dans son projet (étudier la notion de « limites » dans ses aspects les plus divers, de l'art à la littérature, de l'histoire des idées à celle des pratiques sociales) qui a réuni pas moins de 53 auteurs, sont publiés avec finesse et intelligence par Marita Gilli. L'ampleur du champ intellectuel couvert par ces trois volumes ne permet pas d'en rendre compte globalement, mais, parmi les articles plus précisément consacrés à la Révolution française, on retiendra la contribution de Philippe Raxhon, «1789-1889: fins de siècles et jeux de miroir dans le regard catholique belge sur la Révolution française " (vol. 1, pp. 147-158). En plaçant son observation à la fin des années 1880 , époque de grave crise sociale et politique en Belgique, l'auteur nous montre la fracture renouvelée qui sépare les catholiques traditionalistes, qui rejettent en bloc à la fois le discours des Droits de l'homme et celui de la séparation des questions religieuses d'avec le politique, séparation entérinée par le Concordat de 1801, et les catholiques plus libéraux, dans le sillage de Léon XIII et de l'encyclique Rerum Novarum, inquiets de maîtriser la société industrielle qui pointe à l'horizon. Les premiers continuent à rejeter et à diaboliser la Révolution, en se référant sans cesse aux écrits de Burke et de Barruel; les seconds, s'ils ne rejettent pas la 
Révolution en bloc, ils souhaitent ne pas exalter son souvenir et mettre un terme à son influence dans les esprits.

Dans un article très documenté, "Révolution française et consensus au tournant des $\mathrm{XVIII}^{\mathrm{e}}$ et XIX ${ }^{\mathrm{e}}$ siècles » (vol. 2, pp. 336-348), Edna Hindie Lemay présente les débats des États généraux et de l'Assemblée constituante, période de consensus politique assez fort pour la construction de la nouvelle France, puis les parcours différenciés de quelques-uns des protagonistes les plus intéressants des assemblées révolutionnaires suivantes, Le Chapelier, Rabaut-Saint-Étienne, et surtout Lanjuinais, chantre du consensus et de la réconciliation nationale, qui espérait rétablir l'essentiel de la Constitution de 1791 dans la Charte de 1815.

3 L'article nous présente également une intéressante figure de la réflexion politique sous le Directoire, celle de Charles Théremin.

Dans «La rupture révolutionnaire de 1789 et les origines du républicanisme radical » (vol. 2, pp. 349-362), Raymonde Monnier expose «les raisons qui nous font considérer la Révolution comme un laboratoire de la démocratie moderne ", à travers une étude statistique de la présence de certains mots fondateurs comme "démocratie » et de l'expérience vécue par les députés, les magistrats, les militants et tous ceux qui ont découvert le politique et élaboré les pratiques de la représentation et de l'action à divers niveaux, du local au national. La Révolution, en établissant de nouveaux rapports entre la société et l'État, a contribué à remplacer une liberté négative d'obéissance au roi par une liberté positive de participation des citoyens à la chose publique.

Juste après cette réflexion théorique sur les fondements de l'organisation politique de la France à l'époque révolutionnaire, l'article de Michel Biard, «Agents de centralisation ou médiateurs politiques? Entre intendants et préfets, l'expérience des représentants en mission (1793-1795) " (vol. 2, pp. 363-373) explique le rôle de ces agents temporaires du pouvoir qu'ont été les députés, issus de la Convention, envoyés comme "représentants en mission " aux armées ou dans les différents départements. Loin d'être les "proconsuls» plus ou moins sanguinaires décrits par une historiographie malveillante, ces agents du pouvoir exercent une mission le plus souvent brève et très contrôlée. La méthode mise en œuvre par l'auteur consiste à procéder à des aller et retour constants entre le rôle des intendants, celui des représentants en mission et celui des préfets, afin de confronter la figure de chacun des administrateurs qui encadrent le pouvoir central en France. La conclusion de l'article réaffirme l'étroite continuité entre le conventionnel représentant en mission et le préfet, mais aussi la rupture qui s'est opérée en 1795 entre gouvernants et gouvernés.

6 Dans un article très synthétique, «Le début et la fin du siècle des Lumières, lieu de rupture avec retour de la religion en Allemagne» (vol. 2, pp. 376-385), Daniel Minary montre l'acuité du débat sur l'athéisme qui occupe les trois dernières décennies du $\mathrm{xVIII}{ }^{\mathrm{e}}$ siècle après avoir présenté la spécificité très antireligieuse du mouvement des Lumières en Allemagne, lui-même issu d'une douloureuse reconstruction du système des représentations mis à mal par la guerre de Trente Ans. La fin du XvIII ${ }^{\mathrm{e}}$ siècle, comme la fin du XIX ${ }^{e}$ siècle peut être observée comme une seconde situation de rupture avec l'émergence du nouveau rationalisme que constitue le criticisme kantien qui marque bientôt le déclin de l'Aufklärung en Allemagne.

7 Marita Gilli situe son propos dans une perspective très différente, dans un long article consacré à « La sécularisation de la notion de patriotisme en Allemagne à la fin du XVIII ${ }^{\mathrm{e}}$ 
siècle et au début du XIX ${ }^{\mathrm{e}}$ siècle » (vol. 2, pp. 387-401). En Allemagne, comme en France d'ailleurs, l'idéal du bien général et le dévouement à la chose publique sont considérés comme des vertus suprêmes; dans les deux pays, le patriotisme nouveau trouve ses origines dans des mouvements religieux contestataires, le jansénisme en France et le piétisme en Allemagne. Rapidement, avec la Révolution et la dépréciation de la monarchie, la patrie et le patriotisme sont opposés au roi et représentent une légitimité et une dignité supérieure à la sienne. La politisation du patriotisme allemand rend encore plus difficile la rencontre avec les troupes révolutionnaires françaises qui, censées apporter la liberté aux peuples d'outre-Rhin, ne cessent pas d'être des troupes étrangères. Est-il toujours facile d'être cosmopolite et patriote à la fois ? La réponse devait être délicate pour que le premier acte de la Convention rhéno-germanique ait été de demander le rattachement du pays à la France afin que le patriotisme révolutionnaire garde une forte tendance cosmopolite outre-Rhin.

De ce très riche colloque, retenons encore l'article de Helga Boulay, « Le journalisme politique en mutation : l'exemple du Politisches Journal de Gottlob Benedict von Schirach dans les années $1780 »$ (vol. 2, pp. 403-415), ainsi que la mise au point de Gilda Pasetzky, "Salzbourg au tournant entre le XVIII et le $\mathrm{XIX}^{\mathrm{e}}$ siècle: un archevêché entre L’Aufklärung, la Révolution et la sécularisation » (vol. 2, pp. 417-426). 